Article

\title{
Nonlinear Position Control Using Differential Flatness Concept with Load Torque Observer for Electro Hydraulic Actuators with Sinusoidal Load Torque
}

\author{
Sangmin Suh ${ }^{1}\left(\mathbb{D}\right.$, Wonhee $\operatorname{Kim}^{2}{ }^{\mathbb{D}}$ and* \\ 1 Department of Information and Telecommunication Engineering, Gangneung-Wonju National University, \\ Wonju-si 26403, Korea; sangminsuh@gwnu.ac.kr \\ 2 School of Energy Systems Engineering, Chung-Ang University, Seoul 06974, Korea \\ * Correspondence: whkim79@cau.ac.kr
}

Received: 21 August 2020; Accepted: 1 September 2020; Published: 2 September 2020

\begin{abstract}
We propose a nonlinear position control using a differential flatness concept with a load torque observer to compensate for the sinusoidal load torque in electro-hydraulic actuators (EHAs) EHAs. In an EHA with a rotational joint, the load torque is a sinusoidal disturbance, whose magnitude can be estimated via a load torque observer. In the proposed load torque observer, the load torque can be estimated without requiring its maximum frequency to be known. The position controller tracks position and comprises an inner-loop load pressure controller and an outer-loop position controller. The former tracks the desired pressure via near input-output linearization. The desired pressure is developed using the differential flatness of the mechanical system in the EHA. The feedback plus feedforward outer-loop position controller is designed to track the desired position and to compensate for the load torque. The stability of the closed-loop system is mathematically proven using the input-to-state stability property.
\end{abstract}

Keywords: electro hydraulic actuator; load torque observer; position tracking

\section{Introduction}

Electro-hydraulic actuators (EHAs) have been widely used for various positioning and force generation applications e.g., in robots, rolling mills, aircraft actuators, etc. EHAs are advantageous over their electrical counterparts owing to their high power-to-weight ratio [1]. Moreover, EHAs can rapidly generate considerably large forces. However, the control of EHAs is difficult owing to nonlinearities in their dynamic behavior.

Various methods have been developed aimed at controlling the position or the force of an EHA. A linear controller using local linearization of nonlinearities has been applied to EHAs [1]. Variable structure control (VSC) methods were studied to obtain robust control of EHAs in [2-5]. A control method using input-output (IO) linearization has been developed for the control of EHAs without considering servo valve dynamics [6-9]. Since EHA dynamics are in strict feedback form, controllers based on the backstepping procedure have been designed [10-16].

Although the aforementioned approaches enhanced control performance, load torque remains unconsidered. The load torque must be compensated for because it significantly affects EHAs. Practically, it is difficult to directly measure the load torque, so it must be estimated.

Machine learning and statistical framework based methods were proposed to solve the disturbance estimation problem [17-19]. However, these methods require large memory and large calculating time. Control methods based on disturbance observers (DOBs) have been designed to estimate the 
load torque [20-23]. In DOB-based control methods, data regarding the frequency spectrum of the load torque are required to determine the DOB bandwidth; that is, the observer gain. To estimate the load torque, the DOB bandwidth should be wider than the maximum frequency of the load torque. Unfortunately, it may be difficult to know the maximum frequency of the load torque at all times. Utilizing a large observer gain to increase the DOB bandwidth might lead to measurement noise amplification. Consequently, the DOB-based control methods may suffer from the measurement noise amplification. Thus, the observer that does not require the information of the load torque frequency should be designed.

We propose a nonlinear position control using a differential flatness concept with a load torque observer to compensate for the sinusoidal load torque in EHAs where a rotational joint is used as shown in Figure 1. In EHAs with rotational joints, the load torque is a sinusoidal disturbance, whose magnitude can be estimated by a load torque observer. The proposed load torque observer can estimate the load torque without considering its maximum frequency. The position controller is proposed to track position, and comprises an inner-loop load pressure controller and an outer-loop position controller. The inner-loop load pressure controller tracks the desired pressure via near IO linearization. The desired pressure is developed using the differential flatness of the mechanical system in the EHA. The feedback plus feedforward outer-loop position controller tracks the desired position, thus compensating for the load torque. The closed-loop system stability is mathematically proven using the input-to-state stability (ISS) property. The performance of the proposed method is evaluated via simulations. The main contributions of the proposed method are summarized as follows:

- The proposed method improves the position tracking performance under the sinusoidal load torque in EHAs.

- The proposed position controller is designed with the consideration of the EHS dynamics.

- The proposed load torque observer is designed to estimate the load torque without considering its maximum frequency.

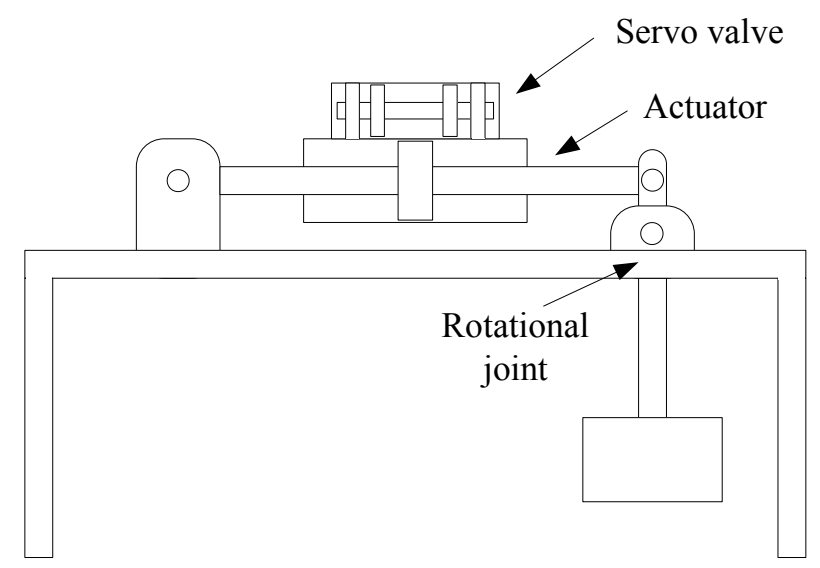

Figure 1. EHA with a rotational joint.

\section{Modeling}

A structure of the EHA is shown in Figure 2. A servo valve is used to control the position of the actuator in the EHA. Generally, servo valve dynamics is sufficiently fast so that we can ignore the servo valve dynamics for the control of the EHA. Therefore,

$$
x_{v}=k_{v} i
$$

where $x_{v}$ is the spool position of the servo-valve $[\mathrm{m}], i$ is the input current of the torque motor [mA], and $k_{v}$ is the torque motor gain $[\mathrm{m} / \mathrm{mA}]$. The cylinder chambers are connected to the servo valve through cylinder ports, and the flow rate of hydraulic fluid in the chambers is controlled by the 
servo valve. The actuator force is generated by the load pressure which is the difference between the pressures at two ports: A and B. The control flow equation of the hydraulic valve for the load flow rate can be expressed [1] as

$$
Q_{L}=C_{d} w x_{v} \sqrt{\frac{1}{\rho}\left(P_{s}-\operatorname{sgn}\left(x_{v}\right) P_{L}\right)}
$$

where $P_{L}$ is the differential pressure between $P_{A}$ and $P_{B}\left[\mathrm{~N} / \mathrm{m}^{2}\right], Q_{L}$ is the load flow rate $\left[\mathrm{m}^{3} / \mathrm{s}\right], C_{d}$ is the discharge coefficient, $w$ is the area gradient of the servo-valve spool $[\mathrm{m}], P_{S}$ is the supply pressure of the pump $\left[\mathrm{N} / \mathrm{m}^{2}\right]$, and $\rho$ is the density of hydraulic oil $\left[\mathrm{kg} / \mathrm{m}^{3}\right]$. By applying the law of continuity to each actuator chamber [1], the load flow rate continuity equation is expressed by (3)

$$
Q_{L}=A \dot{x}_{p}+C_{t l} P_{L}+\frac{V_{t}}{4 \beta_{e}} \dot{P}_{L}
$$

where $x_{p}$ is the piston position [m], $C_{t l}=C_{i l}+\frac{C_{e l}}{2}$ is the total leakage coefficient [m $\left.\mathrm{m}^{5} / \mathrm{Ns}\right], C_{i l}$ is the internal leakage coefficient $\left[\mathrm{m}^{5} / \mathrm{Ns}\right], C_{e l}$ is the external leakage coefficient $\left[\mathrm{m}^{5} / \mathrm{Ns}\right], A$ is the pressure area of the piston $\left[\mathrm{m}^{2}\right], V_{t}$ is the total actuator volume $\left[\mathrm{m}^{3}\right]$, and $\beta_{e}$ is the effective bulk modulus of the system $\left[\mathrm{N} / \mathrm{m}^{2}\right]$. From (2) and (3), the fluid dynamic equation of the actuator is given by

$$
\dot{P}_{L}=-\frac{4 \beta_{e} A}{V_{t}} \dot{x}_{p}-\frac{4 \beta_{e} C_{t l}}{V_{t}} P_{L}+\frac{4 \beta_{e} C_{d} w}{V_{t} \sqrt{\rho}} \sqrt{\left(P_{s}-\operatorname{sgn}\left(x_{v}\right) P_{L}\right)} x_{v}
$$

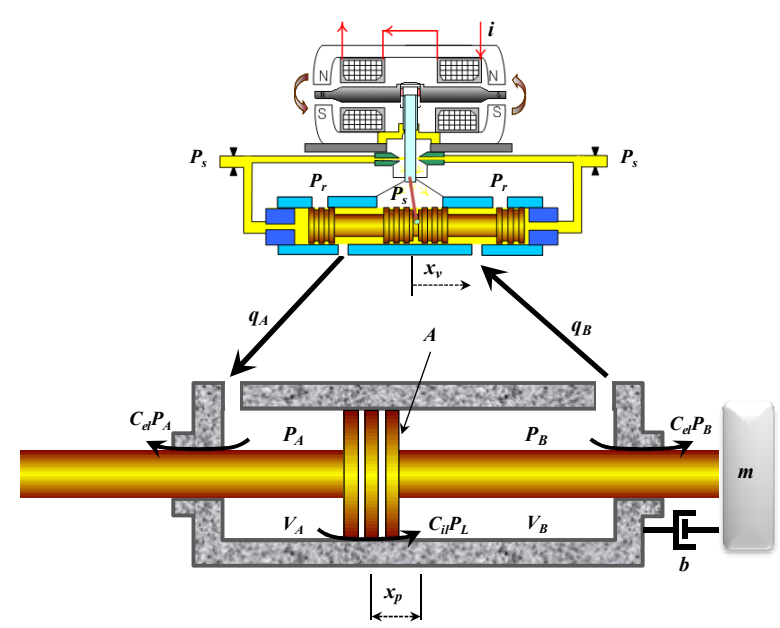

Figure 2. Structure of EHA.

The actuator's force balance equation is expressed as

$$
m \ddot{x}_{p}=-k x_{p}-b \dot{x}_{p}+A P_{L}
$$

where $m$ is the piston mass $[\mathrm{kg}], k$ is the load spring constant $[\mathrm{N} / \mathrm{m}]$, and $b$ is viscous damping coefficient $[\mathrm{N} /(\mathrm{m} / \mathrm{s})]$.

From (1) to (5), the dynamics of the EHA can be obtained as a state-space representation:

$$
\begin{aligned}
& \text { Mechanical system }\left\{\begin{array}{l}
\dot{x}_{1}=x_{2} \\
\dot{x}_{2}=\frac{1}{m}\left(-k x_{1}-b x_{2}+A x_{3}-\tau_{L}\right)
\end{array}\right. \\
& \text { Hydraulic system }\left\{\dot{x}_{3}=-\alpha x_{2}-\beta x_{3}+\gamma \sqrt{P_{s}-\operatorname{sgn}(u) x_{3}} u\right. \\
& \text { System output }\left\{y=x_{1}\right.
\end{aligned}
$$


where $x_{1}$ is the position of the piston $[\mathrm{m}], x_{2}$ is the velocity of the piston $[\mathrm{m} / \mathrm{s}], x_{3}$ is the load pressure $\left[\mathrm{N} / \mathrm{m}^{2}\right], \tau_{L}$ is the load torque, $u$ is the current input $[\mathrm{mA}]$, and $\alpha:=\frac{4 \beta_{e} A}{V_{t}}, \beta:=\frac{4 \beta_{e} C_{t l}}{V_{t}}$, $\gamma:=\frac{4 \beta_{e} C_{d} w k_{v}}{V_{t} \sqrt{\rho}}$.

Figure 1 depicts the problem dealt in this study. In the system, the load torque is in the form of a sinusoidal signal. Thus, $\tau_{L}$ is defined as

$$
\tau_{L}=m_{L} \sin \left(d x_{1}\right)
$$

where $m_{L}$ is the magnitude of the load torque and $d$ is the angular speed of the pendulum. In this study, we assume that $m_{L}$ is an unknown constant.

\section{Controller Design}

\subsection{Position Controller}

In EHA, the piston's movement is generated by the load pressure, implying the desired load pressure design can obtain the desired piston motion. With respect to the mechanical system, the load pressure $x_{3}$ and the position $x_{1}$ can be regarded as the input and the output, respectively. In the mechanical system, all state variables can be parameterized in terms of differential functions of the position except for the load torque. Thus, the mechanical system is clearly differentially flat [24], as the following shows:

$$
m \ddot{x}_{1}+b \dot{x}_{1}+k x_{1}=A x_{3} .
$$

The desired load pressure using flatness is obtained by

$$
x_{3}^{d}=\frac{m \ddot{x}_{1}^{d}+b \dot{x}_{1}^{d}+k x_{1}^{d}}{A} .
$$

The tracking error $e=\left[e_{1}, e_{2}, e_{3}\right]^{T}$ is defined as

$$
\begin{aligned}
& e_{1}=x_{1}-x_{1}^{d} \\
& e_{2}=x_{2}-x_{2}^{*} \\
& e_{3}=x_{3}-x_{3}^{*}
\end{aligned}
$$

where $x_{2}^{*}=\dot{x}_{1}^{d}-K_{1}\left(x_{1}-x_{1}^{d}\right), k_{1}>0, x_{3}^{*}=x_{3}^{d}+h\left(e_{1}, e_{2}, \tau_{L}\right)$, and $h\left(e_{1}, e_{2}, \tau_{L}\right)$ is yet to be defined.

Remark 1. In the previous methods $[8,9], e_{2}$ was defined as $e_{2}=x_{2}-\dot{x}_{1}^{d}$. Thus, the previous control methods were developed to reduce the position tracking error $e_{1}$ and the velocity tracking error $e_{2}$ to zero. However, converging $e_{1}$ and $e_{2}$ simultaneously to zero in physical systems can be challenging. Therefore, in order to enhance position tracking performance, $e_{2}=x_{2}-x_{2}^{*}$ is used instead of $e_{2}=x_{2}-\dot{x}_{1}^{d}$.

Proposition 1. If the near IO linearizing inner-loop controller designed as

$$
u=\frac{1}{\gamma \sqrt{P_{s}-\operatorname{sgn}(u) x_{3}}}\left[\alpha x_{2}+\beta x_{3}-K_{3}\left(x_{3}-x_{3}^{*}\right)+\dot{x}_{3}^{*}\right]
$$

where $K_{3}>0$ is applied to the load pressure $x_{3}$ dynamics (6), then $e_{3}$ converges to zero exponentially

Proof. In the EHA (6), $x_{3}$ dynamics are

$$
\dot{x}_{3}=-\alpha x_{2}-\beta x_{3}+\gamma \sqrt{P_{s}-\operatorname{sgn}(u) x_{3}} u
$$


With the near IO linearizing inner-loop controller (11), $e_{3}$ dynamics become

$$
\begin{aligned}
\dot{e}_{3} & =\dot{x}_{3}-\dot{x}_{3}^{*} \\
& =-\alpha x_{2}-\beta x_{3}+\gamma \sqrt{P_{s}-\operatorname{sgn}(u) x_{3}} u-x_{3}^{*} \\
& =-k_{3} e_{3} .
\end{aligned}
$$

Therefore, $e_{3}$ converges to zero exponentially.

Remark 2. Due to the presence of control variable $u$ on both sides of the equality, the control law (11) cannot be solved in its present condition. However, in the digital implementation of the control law, the sign of the value of $u$ at the previous time step can be used to compute the control law (11) at the current time step, provided that $u$ does not change sign at a rate faster than the sampling rate; thus, the approximated value can be obtained.

Next, for position tracking with load torque compensation, the feedback plus feedforward outer-loop position tracking controller $h\left(e_{1}, e_{2}, \tau_{L}\right)$ is designed to compensate for the load torque as

$$
h\left(e_{1}, e_{2}, \tau_{L}\right)=\frac{1}{A}\left[\left(k-b K_{1}-m K_{1}^{2}\right) e_{1}+\left(b+m K_{1}-m K_{2}\right) e_{2}+\tau_{L}\right] .
$$

where $K_{1}$ and $K_{2}$ are control gains.

Theorem 1. Suppose that the control laws (11) and (14) are applied to the $E H A$, if the control gains $K_{1}, K_{2}$, and $K_{3}$ are positive constants, then e converges to zero exponentially.

Proof. The mechanical system can be rewritten by

$$
m \ddot{x}_{1}+b \dot{x}_{1}+k x_{1}+\tau_{L}=A\left(e_{3}+x_{3}^{*}\right) .
$$

With the control laws (11), (14), and (15), we obtain

$$
m \dot{e}_{2}+m K_{2} e_{2}=A e_{3} .
$$

With $x_{2}^{*}=\dot{x}_{1}^{d}-K_{1}\left(x_{1}-x_{1}^{d}\right),(13)$, and (16), the tracking error dynamics are

$$
\left[\begin{array}{l}
\dot{e}_{1} \\
\dot{e}_{2} \\
\dot{e}_{3}
\end{array}\right]=\underbrace{\left[\begin{array}{ccc}
-K_{1} & 1 & 0 \\
0 & -K_{2} & \frac{A}{m} \\
0 & 0 & -K_{3}
\end{array}\right]}_{A_{e}}\left[\begin{array}{l}
e_{1} \\
e_{2} \\
e_{3}
\end{array}\right] .
$$

If the control gains $K_{1}, K_{2}$, and $K_{3}$ are positive constant, $e$ converges to zero exponentially.

\subsection{Load Torque Observer}

In the load torque (7), $m_{L}$ is an unknown constant. To estimate $m_{L}, \hat{m}_{L}$ is defined as the estimation of $m_{L}$. In this paper, we assume that full state variables are measurable. Thus, the load torque observer to estimate $m_{L}$ is designed as follows:

$$
\begin{aligned}
\hat{m}_{L} & =z-K_{a} x_{1} x_{2}^{\mu} \\
\dot{z} & =\frac{K_{a} \mu x_{2}^{\mu-1} x_{1}}{m}\left(-k x_{1}-b x_{2}+A x_{3}-\hat{m}_{L} \sin \left(d x_{1}\right)\right)+K_{a} x_{2}^{\mu+1}
\end{aligned}
$$

where $K_{a}$ is a positive constant and $\mu$ is a positive odd integer. In order to study the stability of the load torque observer (18), the estimation error $\tilde{m}_{L}$ is defined as 


$$
\tilde{m}_{L}=m_{L}-\hat{m}_{L}
$$

Theorem 2. If the load torque observer (18) is applied to the EHA, then $\tilde{m}_{L}$ locally and asymptotically converges to zero.

Proof. The estimation error dynamics are

$$
\begin{aligned}
\dot{\tilde{m}}_{L} & =-\dot{\hat{m}}_{L} \\
& =-\dot{z}+K_{a} \dot{x}_{1} x_{2}^{\mu}+\mu K_{a} x_{1} x_{2}^{\mu-1} \dot{x}_{2} \\
& =-\frac{\mu K_{a} x_{2}^{\mu-1}}{m} x_{1} \sin \left(d x_{1}\right) \tilde{m}_{L} .
\end{aligned}
$$

Therefore, $\tilde{m}_{L}$ locally and asymptotically converges to zero.

Consequently, the estimated load torque can be obtained as

$$
\hat{\tau}_{L}=\hat{m}_{L} \sin \left(d x_{1}\right) .
$$

\subsection{Stability Analysis of the Closed-Loop System}

The position controller (11) and (14) and the load torque observer (18) are designed separately. In fact, the estimated load torque is used in the position controller instead of the load torque. Therefore, from now on, the stability of the closed-loop including both the position controller (11) and (14) and the load torque observer (18) are mathematically proven.

Theorem 3. Suppose that the position controller (11) and (14) and the load torque observer (18) are applied to the EHA. If $A_{e}$ is Hurwitz, $K_{a}$ is a positive constant and $\mu$ is a positive odd integer; then, e locally and asymptotically converges to zero.

Proof. Because $\hat{m}_{L}$ is used in the position controller, $\hat{e}_{3}, \hat{x}_{3}^{*}$, and $\hat{h}\left(e_{1}, \dot{e}_{1}, \hat{\tau}_{L}\right)$ are defined as

$$
\begin{aligned}
\hat{e}_{3} & =x_{3}-\hat{x}_{3}^{*} \\
\hat{x}_{3}^{*} & =x_{3}^{d}+\hat{h}\left(e_{1}, \dot{e}_{1}, \hat{\tau}_{L}\right) \\
\hat{h}\left(e_{1}, e_{2}, \hat{\tau}_{L}\right) & =\frac{1}{A}\left[\left(k-b K_{1}-m K_{1}^{2}\right) e_{1}+\left(b+m K_{1}-m K_{2}\right) e_{2}+\hat{\tau}_{L}\right] .
\end{aligned}
$$

We define $\hat{e}=\left[e_{1}, e_{2}, \hat{e}_{3}\right]^{T}$. Then, the closed-loop system is obtained as

$$
\begin{aligned}
{\left[\begin{array}{l}
\dot{e}_{1} \\
\dot{e}_{2} \\
\dot{e}_{3}
\end{array}\right]=\underbrace{\left[\begin{array}{ccc}
-K_{1} & 1 & 0 \\
0 & -K_{2} & \frac{A}{m} \\
0 & 0 & -K_{3}
\end{array}\right]}_{A_{e}}\left[\begin{array}{l}
e_{1} \\
e_{2} \\
\hat{e}_{3}
\end{array}\right]-\underbrace{\left[\begin{array}{c}
0 \\
\sin \left(d x_{1}\right) \\
0
\end{array}\right]}_{B_{e}\left(x_{1}\right)} \tilde{m}_{L} } \\
\dot{\tilde{m}}_{L}=-\frac{\mu K_{a} x_{2}^{\mu-1}}{m} x_{1} \sin \left(d x_{1}\right) \tilde{m}_{L}
\end{aligned}
$$

$B_{e}\left(x_{1}\right)$ is ultimately bounded. Thus, if $A_{e}$ is Hurwitz, then the dynamics of $\hat{e}$ have the ISS property. $\tilde{m}_{L}$ converges locally and asymptotically to zero unless $K_{a}$ is a positive constant and $\mu$ is a positive odd integer. Therefore, $\hat{e}$ converges locally and asymptotically to zero. Because $e_{3}=\hat{e}_{3}-\tilde{m}_{L} \sin \left(d x_{1}\right)$, $e_{3}$ also converges locally and asymptotically to zero.

The block diagram of the overall control system for the EHA is shown in Figure 3. The desired load pressure $x_{3}^{d}$ is derived using (9) according to the desired position. The load torque observer (18) and (21) 
estimates the load torque. Then, $x_{3}^{*}$ is obtained using the outer-loop controller (14). Finally, the control input $u$ is obtained by the inner-loop controller (11).

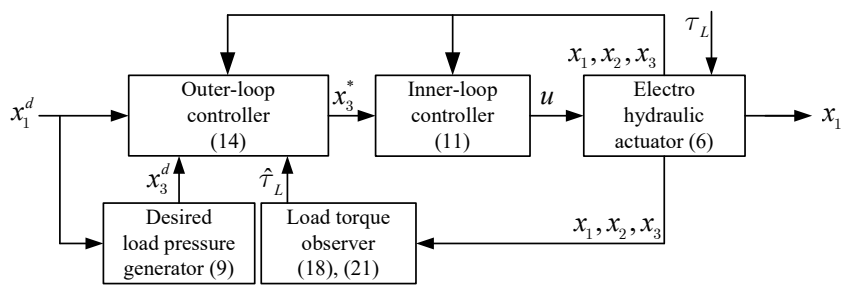

Figure 3. Block diagram of the overall control system for the EHA.

\section{Simulations}

Simulations were conducted to validate the proposed method using MATLAB/Simulink. The EHA system model used in this simulations was designed using the SimHydraulic model. The measurement noises that were $0.035 \%$ and $0.15 \%$ of the maximum ranges in the position sensor and the pressure sensor, respectively, were used. The parameters of the EHA used, including control and observer gains, are as follows: $m=0.5, A=5.058 \times 10^{-4}, k=0, b=0, \alpha=3.2569 \times 10^{10}$, $\beta=2.1456, \gamma=7.1693 \times 10^{9}=k_{v}=1.3333 \times 10^{-5}, K_{1}=200, K_{2}=3000, K_{3}=10,000, \mu=1 . K_{a}=30,000$, and $d=62.8319 . x_{1}^{d}=0.015\left(1-e^{-10 t}\right) \sin (2 \pi t)$ was used as the desired position. Simulations were tested for the following two cases: (1) $m_{L}$ is constant, i.e., the load torque is $\tau_{L}=98 \sin \left(62.8 x_{1}\right)$; (2) $m_{L}$ is time-varying, i.e., the load torque is $\tau_{L}=98(1+\sin (6 \pi t)) \sin \left(62.8 x_{1}\right)$.

\subsection{Case 1}

Figure 4 shows the simulation results for case 1 . Because $\mu=1$, the convergence rate of the load torque observer (18) depends only on $x_{1}$. At the beginning, because $x_{1}$ was near zero, the convergence rate of the estimation was low. However, the estimated magnitude converged to the actual magnitude as soon as $x_{1}$ moved away from zero. The position tracking error was relatively large at the beginning due to the failure of load torque estimation. After $0.1 \mathrm{~s}$, because the load torque was compensated, $x_{1}$ tracked $x_{1}^{d}$ well as shown in Figure 4a,b.

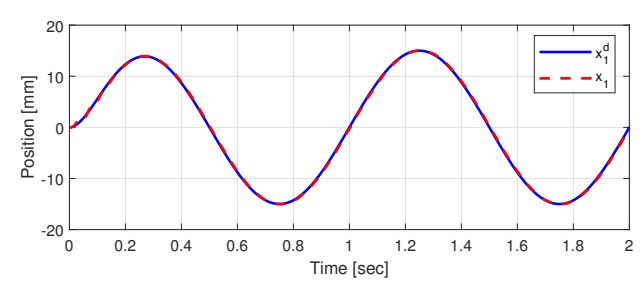

(a) Position tracking performance $\left(x_{1}\right.$ and $\left.x_{1}^{d}\right)$

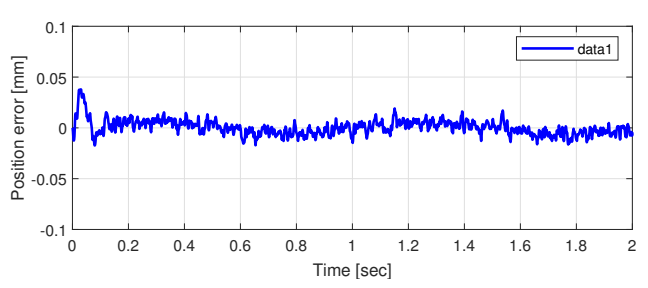

(b) Position tracking error $\left(e_{1}\right)$

Figure 4. Cont. 


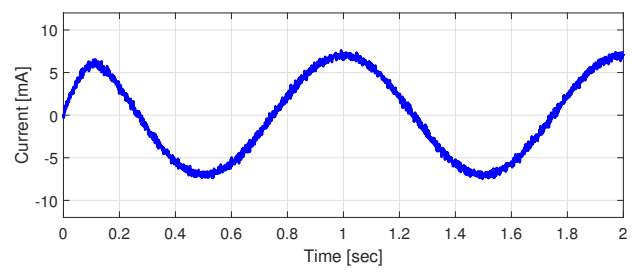

(c) Current $(u)$

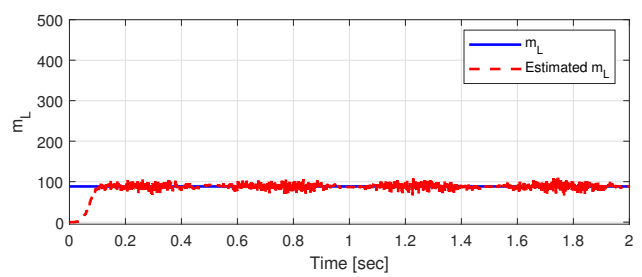

(d) Magnitude of the load torque $\left(m_{L}\right)$

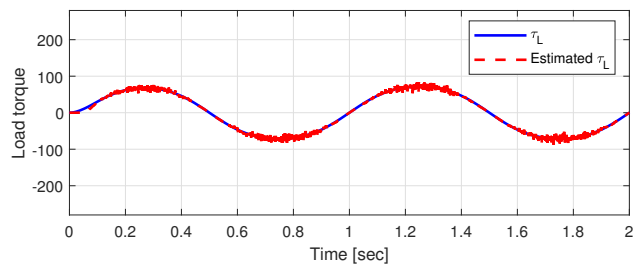

(e) Load torque $\left(\tau_{L}\right)$

Figure 4. Simulation results for Case 1: position tracking performance $\left(x_{1}\right.$ and $\left.x_{1}^{d}\right)(\mathbf{a})$, position tracking error $\left(e_{1}\right)(\mathbf{b})$, current $(u)(\mathbf{c})$, magnitude of the load torque $\left(m_{L}\right)(\mathbf{d})$ and Load torque $\left(\tau_{L}\right)(\mathbf{e})$.

\subsection{Case 2}

In Case 2, the estimation performance for the time-varying magnitude of the load torque, i.e., $m_{L}=98(1+\sin (6 \pi t))$ was tested. Figure 5 shows the simulation results of case 2 are shown. Estimation of the load torque magnitude failed because $x_{1}$ was near zero at the outset, as shown in Figure 5d. However, the estimated magnitude of the load torque converged to the actual magnitude again once $x_{1}$ was far from zero. Because the desired position $x_{1}^{d}$ is a sinusoidal signal, this situation occurred repeatedly. Although estimation of load torque magnitude failed near $x_{1}=0$, its estimation error was relatively small since $\sin \left(d x_{1}\right)$ is minute near $x_{1}=0$. Therefore, the failure to estimate the load torque magnitude did not significantly affect position tracking performance. 


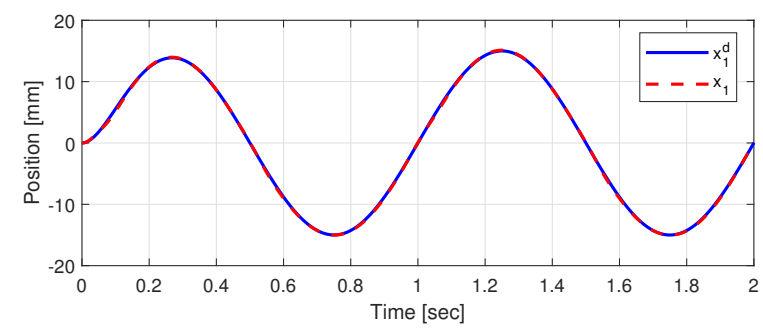

(a) Position tracking performance $\left(x_{1}\right.$ and $\left.x_{1}^{d}\right)$

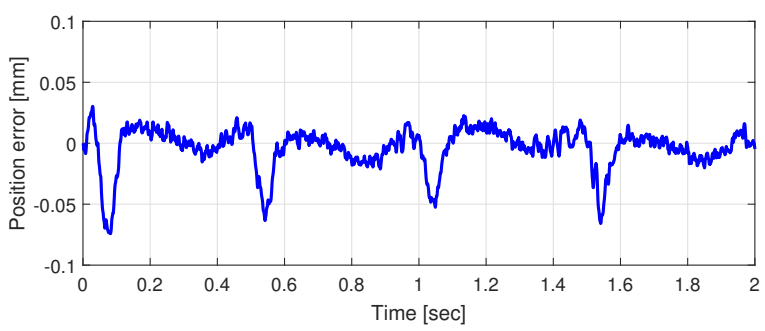

(b) Position tracking error $\left(e_{1}\right)$

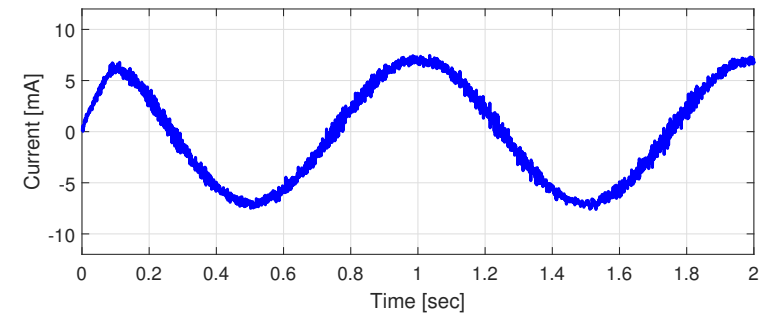

(c) Current $(u)$

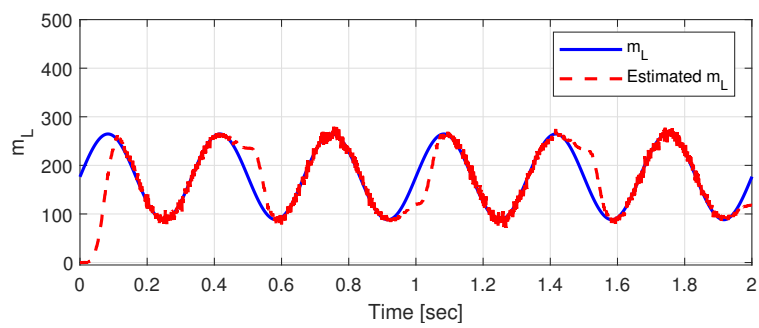

(d) Magnitude of the load torque $\left(m_{L}\right)$

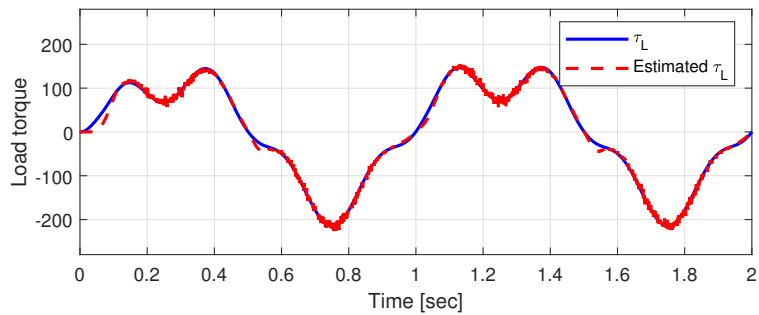

(e) Load torque $\left(\tau_{L}\right)$

Figure 5. Simulation results for Case 2: position tracking performance $\left(x_{1}\right.$ and $\left.x_{1}^{d}\right)$ (a), position tracking error $\left(e_{1}\right)(\mathbf{b})$, current $(u)(\mathbf{c})$, magnitude of the load torque $\left(m_{L}\right)(\mathbf{d})$ and Load torque $\left(\tau_{L}\right)(\mathbf{e})$.

\section{Conclusions}

This study proposed a nonlinear position control using the differential flatness concept with a load torque observer for EHAs. The load torque observer estimates the sinusoidal load torque 
magnitude. The proposed load torque observer does not require maximum frequency of the load torque to estimate the load torque. The position controller tracks position and comprises an inner-loop load pressure controller and an outer-loop position controller. The former tracks the desired pressure via near IO linearization. The desired pressure was developed using the differential flatness of the mechanical system of the EHA. Simulations confirmed performance of load torque estimation and position tracking using the proposed method. It was observed that the load torque was estimated well under the measurement noise and the good position tracking performance was obtained.

Author Contributions: Conceptualization, S.S.; investigation, W.K. and S.S.; methodology, S.S.; writing-original draft preparation, S.S.; writing-review and editing, W.K.; funding acquisition, W.K. All authors have read and agreed to the published version of the manuscript.

Funding: This research was supported by the Energy Cloud R\&D Program through the National Research Foundation of Korea(NRF) funded by the Ministry of Science, ICT (2019M3F2A1073313).

Conflicts of Interest: The authors declare no conflict of interest.

\section{References}

1. Merrit, H.E. Hydraulic Control System; Wiley and Sons: New York, NY, USA, 1967.

2. Chen, T.; Wu, Y. An optimal variable structure control with integral compensation for electrohydraulic position servo control systems. IEEE Trans. Ind. Elec. 1992, 39, 460-463 [CrossRef]

3. Jerouane, M.; Lamnabhi-Lagarrigue, F. A new sliding mode controller for a hydraulic actuators. In Proceedings of the Conference on Decision and Control, Orlando, FL, USA, 4-7 December 2001; pp. 908-913

4. Bonchis, A.; Corke, P.I.; Rye, D.C.; Ha, Q.P. Variable structure methods in hydraulic servo systems control. Automatica 2001, 37, 589-595. [CrossRef]

5. Li, Y.; He, L. Counterbalancing speed control for hydrostatic drive heavy vehicle under longdown-slope. IEEE/ASME Trans. Mechatron. 2015, 20, 1533-1542. [CrossRef]

6. Hahn, H.; Piepenbrink, A.; Leimbach, K.-D. Input/output linearization control of an electro servo-hydraulic actuator. In Proceedings of the IEEE 1994 Conference on Control Applications, Glasgow, UK, 24-26 August 1994; pp. 995-1000.

7. Vossoughi, G.; Donath, M. Dynamic feedback linearization for electrohydraulically actuated control systems. J. Dyn. Syst. Meas. Control 1995, 117, 468-477. [CrossRef]

8. Eryilmaz, B.; Wilson, B.H. Improved Tracking Control of Hydraulic Systems. J. Dyn. Syst. Meas. Control 2001, 123, 457-462. [CrossRef]

9. Ayalew, B.; Kulakowski, B.T. Cascade tuning for nonlinear position control of an electro-hydraulic actuator. In Proceedings of the IEEE 2006 American Control Conference, Minneapolis, MN, USA, 14-16 June 2006; pp. 4627-4632.

10. Alleyne, A.; Liu, R. Systematic control of a class of nonlinear systems with application to electrohydraulic cylinder pressure control. IEEE Trans. Control Syst. Technol. 2000, 8, 623-634. [CrossRef]

11. Yao, B.; Bu, F.; Reedy, J.; Chiu, G.T.-C. Adaptive robust motion control of single-rod hydraulic actuators: Theory and experiments. IEEE/ASME Trans. Mechatron. 2000, 5, 79-91.

12. Kaddissi, C.; Kenné, J.; Saad, M. Identification and real-time control of an electrohydraulic servo system based on nonlinear backstepping. IEEE/ASME Trans. Mechatron. 2007, 12, 12-22. [CrossRef]

13. Zeng H.; Sepehri, N. Tracking control of hydraulic actuators using a LuGre friction model compensation. ASME J. Dyn. Syst. Meas. Control 2008, 120, 014502. [CrossRef]

14. Guan, C.; Pan, S. Nonlinear adaptive robust control of single-rod electro-hydraulic actuator with unknown nonlinear parameters. IEEE Trans. Control Syst. Technol. 2008, 16, 434-445. [CrossRef]

15. Kim, W.; Won, D.; Shin, D.; Chung, C.C. Output feedback nonlinear control for electro-hydraulic systems. Mechatronics 2012, 22, 766-777. [CrossRef]

16. Won, D.; Kim, W.; Tomizuka, M. High gain observer based integral sliding mode control for position tracking of electro-hydraulic systems. IEEE/ASME Trans. Mechatron. 2017, 22, 2695-2704. [CrossRef] 
17. Wrat, G.; Ranjan, P.; Bhola, M.; Mishra, S.K.; Das, J. Position control and performance analysis of hydraulic system using two pump-controlling strategies. Proc. Inst. Mech. Eng. Part I J. Syst. Control Eng. 2019, 233, 1093-1105. [CrossRef]

18. Imani, M.; Ghoreishi, S.F.; Braga-Neto, U.M. Bayesian control of large MDPs with unknown dynamics in data-poor environments. In Proceedings of the Advances in Neural Information Processing Systems, Montreal, QC, Canada, 3-8 December 2018; pp. 8146-8156.

19. Banerjee, S.; Samynathan, B.; Abraham, J.; Chatterjee, A. Real-time error detection in nonlinear control systems using machine learning assisted state-space encoding. IEEE Trans. Depend. Secur. Comput. 2019. [CrossRef]

20. Won, D.; Kim, W.; Shin, D.; Chung, C.C. High gain disturbance observer based backstepping control with output tracking error constraint for electro-hydraulic systems. IEEE Trans. Control Syst. Technol. 2015, 23, 787-795. [CrossRef]

21. Guo, Q.; Zhang, M.Y.; Celler, B.G.; Su, S.W. Backstepping control of electro-hydraulic system based on extended-state-observer with plant dynamics largely unknown. IEEE Trans. Ind. Electron. 2016, 63, 6909-6920. [CrossRef]

22. Wang, C.; Quan, L.; Zhang, S.; Meng, H.; Lan, Y. Reduced-order model based active disturbance rejection control of hydraulic servo system with singular value perturbation theory. ISA Trans. 2017, 67, 455-465. [CrossRef] [PubMed]

23. Won, D.; Kim, W.; Tomizuka, M. Nonlinear control with high gain extended state observer for position tracking of electro-hydraulic systems. IEEE/ASME Trans. Mechatron. 2020. [CrossRef]

24. Fliess, M.; Lévine, J.; Martin, P.; Rouchon, P. Flatness and defect of non-linear systems: Introductory theory and examples. Int. J. Control 1995, 61, 1327-1361. [CrossRef]

(C) 2020 by the authors. Licensee MDPI, Basel, Switzerland. This article is an open access article distributed under the terms and conditions of the Creative Commons Attribution (CC BY) license (http:/ / creativecommons.org/licenses/by/4.0/). 